\title{
Comparative analysis of decision-making methodologies used in environmental planning
}

\author{
S. Bakopoulou, S. Polyzos \& A. Kungolos \\ Department of Planning and Regional Development, \\ University of Thessaly, Volos, Greece
}

\begin{abstract}
It is the objective of this study to analyze the methodologies used for the evaluation of alternative projects in the environmental planning procedure. There are many methodologies used for evaluation of a project or alternative actions such as financial analysis, cost effectiveness analysis, cost benefit analysis and multicriteria analysis. The main methodologies that are being considered in this study are cost benefit analysis and multicriteria analysis. They are two basic methodologies which facilitate the decision-making procedure especially in cases where many criteria should be taken into account in the decision-making model. The character of data being worked out by each methodology differs. Cost benefit analysis is a monetary based technique and all variables should have a monetary value while multicriteria analysis is a non-monetary technique and it can incorporate qualitative variables. The advantages and disadvantages of each methodology are being discussed in the study in order to find a methodology suitable for evaluating alternative actions under the sustainability concept.
\end{abstract}

Keywords: decision-making, evaluation methodologies, environmental planning.

\section{Introduction}

Dealing with any decision problem, the intent is to select the best alternative choice among those available or to create alternative choices better than those readily apparent. Determining what is a good, better or best decision is a value judgement (Keeney [1], Gough and Ward [2]). Without taking in mind values judgements, the decision-making process will fail.

The concept of "good" decision may relate to the decision-making process or it may relate to the outcomes of the decision. Decisions involve taking risks and, 
from this perspective, good process and good outcomes are linked by probabilities. If good process is followed and there is minimal uncertainty involved, then there is a high probability that the final outcome will be good. Environmental decisions, however, tend to have considerable uncertainty associated with them. In these circumstances, the link between good process and good outcome is less certain. Thus, there can be two views as to what constitutes a good decision. On the one hand there is the view that the decision is good if the outcome is good. In this case, whether the decision is good cannot be determined until after the event. The other perspective is that the decision is good if the process followed is good, and this process may be independent of the outcomes. In reality, the concept of a good decision will involve elements of both criteria and weighting given to them. In the context of environmental decision-making, it may be a long time before the outcomes are known, and therefore the process aspect may be weighed more heavily (Gough and Ward [2]).

On the other hand, the concepts of environmental planning and decisionmaking are based upon conflict analyses characterized by socio-political, environmental and economic value judgements. Several alternatives have to be considered and evaluated in terms of many and different criteria, resulting into a vast body of data that are often inaccurate or uncertain. To complicate the process further, there are typically a large number of decision-makers with conflicting preferences. The different points of view of various interest groups should also be considered in the process (Lahdelma et al. [3]).

Taking in mind the above information, it can be concluded that procedure of making a really good and simple decision does not exist in environmental planning, and the planning process can be characterized as a search for acceptable compromise solutions. Success of this process depends on selecting the most suitable decision-making methodology. In the following sections, we present a comparative analysis of such methodologies in an effort to search for a methodology suitable for evaluating alternative actions or choices under sustainability concept.

\section{Decision-making procedure}

Decision-making procedure about proposals for future action should normally follow the sequence below (Dodgson et al. [4], Johansson et al. [5]):

- identifying the problem and the objectives;

- identifying options for achieving the objectives;

- identifying the criteria to be used to compare the options;

- analysis of the options;

- making choices; and

- feedback.

The steps of identifying suitable options as well as suitable criteria for achieving the objectives are critical in success of the procedure. The options should be selected having in mind the possibility of modifying or adding new data to them, since they often change. The criteria should carefully be selected 
and organized in a hierarchy, often referred to as a value tree. The notions of criteria scoring and weighting are also critical in success of the procedure. During scoring procedure, the key idea is to construct scales representing decision maker's preferences or values. A high value will be given to the most preferred outcome and a low value to the least preferred one. During the weighting procedure, the weight is chosen based on the importance of the criteria used for making the decision (Johansson et al. [5]). The Figure 1 describes the procedure analyzed above.

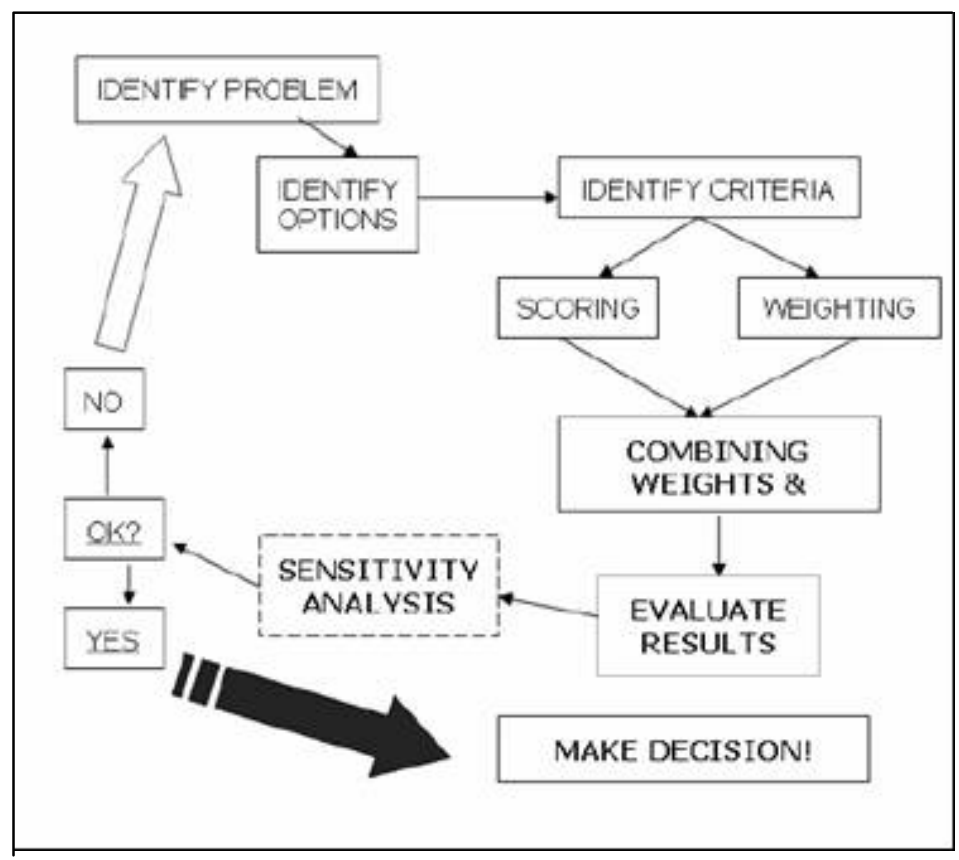

Figure 1: Main steps followed during decision-making procedure (Johansson et al. [5]).

Another crucial point regarding decision-making procedure relates to stakeholders involvement. The decision-making procedure is being affected not only by the decision maker, but also by stakeholders. The stakeholders are all the different people associated with the planning and decision process. In the beginning of the process one should identify all stakeholders and explicitly determine who should participate in the planning process, in which phases, and to what extent. There must be explicit and convincing arguments for adding or dropping a stakeholder (Lahdelma et al. [3]). The involvement of stakeholders in decision-making procedure is critical in highlighting different aspects of the problems and identifying aspects needing further research. 


\section{Decision-making methodologies}

The methodologies that are widely used in decision-making procedure can be categorized in the following general groups (Dodgson et al. [4]): (a) monetary based techniques and (b) non-monetary-based techniques. The monetary based techniques include financial analysis, cost effectiveness analysis, and cost benefit analysis. Cost benefit analysis is the most important one and it has been used all over the world during the last years in order to evaluate projects related to environmental planning. The non-monetary-based techniques include all the methodologies used in multicriteria analysis. Multicriteria analysis is also an extremely useful method used for decision-making and evaluation of environmental projects.

A short presentation of cost benefit analysis and multicriteria analysis follows in next sections.

\subsection{Cost benefit analysis}

Cost-benefit analysis (CBA) seeks to value the expected impacts of an option in monetary terms. These valuations are based on a well-developed economic theory of valuation based on willingness-to-pay or to accept. This theory can act as a guide to how valuation should be achieved. The valuations are based on the willingness to pay of the potential gainers for the benefits they will receive as a result of the option, and the willingness of potential losers to accept compensation for the losses they will incur. In principle, a project is desirable if the benefits exceed the losses, suitably discounted over time (Dodgson et al. [4]). There are many methods used for valuation of non market goods and services such as travel cost method, hedonic pricing method, and contingent valuation method. Some of these methods are grouped to revealed preference techniques, while some others are included in stated preference techniques. Revealed preference approach use observed price information of monetary goods in order to indirectly valuate non market goods such as environmental goods. Stated preference methods seek more direct consumer valuations of environmental effects by asking individuals about their willingness-to-pay, or willingness to accept compensation, for specified changes in environmental quality (Bithas [6], Vlahou [7]).

\subsection{Multicriteria analysis}

Multicriteria analysis or multicriteria decision analysis (MCA / MCDA) is an approach helping decision makers to effectively handle complex decision situations. MCA methods can be characterized as appropriate tools to support a decision-making process characterized by conflicts (Refsgaard [8]). MCA analysis establishes preferences between options by reference to an explicit set of objectives that the decision-making body has identified, and for which it has established measurable criteria to assess the extent to which the objectives have been achieved. The decision-making body usually includes the decision makers and other stakeholders. The criteria for assessing the extent to which the 
alternatives have been achieved may be both quantitative and qualitative (Refsgaard [8], Dodgson et al. [4]).

All MCA approaches require the exercise of judgement. They differ in how they combine the data. MCA techniques can be used to identify a single most preferred option, to rank options, to short-list a limited number of options for subsequent detailed appraisal, or simply to distinguish acceptable from unacceptable possibilities (Dodgson et al. [4]).

The majority of specialists (Roy and Vincke [9], Vincke [10], Lahdelma et al. [3]) agree that MCA methods can be divided into three groups:

- Methods based on utility function (e.g. AHP, UTA, distance based techniques) that aggregate different criteria (points of view) into one global criterion, called utility function; those methods eliminate incomparability between variants.

- Methods based on the outranking relation (e.g. ELECTRE, PROMETHEE), that take into account the incomparability between variants.

- Interactive methods (e.g. multiobjective mathematical programming), that are based on the "trial and error" approach; those methods are characterized by phases of computation alternating with phases of decision-making.

The methods included in first and second group are most popular and have been used for resolving complex environmental problems in recent years.

\section{Comparative analysis of cost benefit analysis and multicriteria analysis used in environmental planning problems}

The key feature in environmental planning decision problems is to find a proper decision model for complex issues. The reason for this complexity is that environmental problems are multifactorial and they are often characterized by significant conflicts.

A cost benefit analysis is an example of a rational choice based technique which emphasizes in maximising an objective function subject to constraints. It has been used for evaluation of projects with an impact on the environment with the overall objective of maximising social welfare. CBA is based on real or simulated markets where people are defined as "consumers". Their willingness to pay for buying a good is used for placing monetary values on non market goods (Refsgaard [8]). The "consumer" definition during a decision-making procedure in environmental planning is risky since environmental planning is a participative procedure and the decision maker should act more like citizen than like consumer. In environmental planning decision problems, the decision makers and the stakeholders should try to value goods from a wider perspective taking into account not only their own ethical values, but also other people's interests and values. So, it can easily be concluded that multicriteria analysis is more suitable than cost benefit analysis in building a participative model which incorporates the notion of dialogue about conflicting issues and different values. The only disadvantage of MCA methods is that they cannot show that an action 
adds more to welfare than it detracts since they lack a notion saying that benefits should exceed costs in order to achieve the maximum social welfare.

Another crucial advantage of multicriteria analysis against cost benefit analysis relates to the fact that $\mathrm{CBA}$ is only restricted to evaluation of quantitative variables while MCA can evaluate both quantitative and qualitative data (Refsgaard [8], Dodgson et al. [4]). Taking into account the multifactorial character of environmental problems, we can easily conclude that application of CBA for resolving an environmental problem will never lead to satisfactory solutions. On the other hand, CBA is a method where all variables can be measured in a common monetary unit. This means that the gains of any criterion can be traded off against the losses of other criteria. However, the complexity that characterizes environmental processes makes the use of substitution risky since important information may be lost because of trade offs. Multicriteria methods and especially outranking techniques are more suitable to be used in such cases.

On the other hand, a key feature of MCA methods, which has been a matter of concern, relates to the fact they are characterized as subjective methods while CBA methods are generally objective methods (Dodgson et al. [4]). This subjectivity stems from emphasis of MCA on the judgement of the decisionmaking team in establishing objectives and criteria, estimating relative importance of weights and, to some extent, in judging the contribution of each option to each performance criterion. This subjectivity, however, can be important since, thus, MCA can bring a degree of structure, analysis and openness to classes of decision that lie beyond the practical reach of CBA.

It is also important to stress that MCA is not a tool providing the right solution in a decision problem in the way that CBA provides. However in environmental planning, no such solutions exist (Diakoulaki and Mavrotas [11]). MCA is an aid to decision-making procedure that helps stakeholders to organize the available information, think on the consequences, explore their own wishes and tolerances and minimize the possibility for a post-decision disappointment.

\section{Conclusions}

Taking in mind the above analysis, we can easily conclude that multicriteria analysis methods present specific advantages when they are used for evaluation of decision problems in environmental planning. Complexity of environmental problems can simply be modelled by the majority of multicriteria analysis methods because of their ability to process different and conflicting values.

However, in many cases and especially in cases where economic criteria should be evaluated with social, environmental and technical criteria in the same model, cost benefit analysis can be successfully applied. The use of cost benefit analysis in evaluation of economic criteria is critical in analyzing the way that every alternative action adds to welfare of the society. Results of cost benefit analysis can then be included in multicriteria analysis, so as to produce a model which incorporates all the relevant criteria in a holistic way. Thus, we believe that combined use of cost benefit analysis and multicriteria analysis is suitable 
for resolving sustainability problems whose aim is the reconciliation of economic, environmental, and social values.

\section{Acknowledgements}

This study is part of a work mainly funded by the Greek General Secreteriat for Research and Technology (Ministry of Development) as well as co-funded by Municipal Sewage and Watering Enterprise of Larissa. Thus, the authors would like to thank the above institutes for their important support in our work.

\section{References}

[1] Keeney, R. "Building models of values", European Journal of Operational Research, 37: 149-157, 1988.

[2] Gough, J. and Ward, J. "Environmental decision-making and lake management", Journal of Environmental Management, 48: 1-15, 1996.

[3] Lahdelma, R., Salminen, P., Hokkanen, J. "Using multicriteria methods in environmental planning and management", Environmental Management, 26 (6): 595-605, 2000.

[4] Dodgson, J., Spackman, M., Pearman, A., Phillips L. "Dept of Transport, Local Govt \& the Regions multi-criteria analysis manual", available at http://www.communities.gov.uk/pub/252/MulticriteriaanalysismanualPDF 1380Kb_id1142252.pdf.

[5] Johansson, E., Lekawska, L., Nilsson, M. "Multiple criteria decision analysis -MCDA, the tool for future decision aid", Report sheet, Stockholm, 2006.

[6] Bithas, K. An economic consideration of environment protection procedure, Tipothito publications, Athens, 2003. (in Greek)

[7] Vlahou, A. Environment and Natural Resources: Economic theory and policy, Kritiki publications, Athens, 2001. (in Greek)

[8] Refsgaard, K. "Process-guided multicriteria analysis in wastewater planning", Environment and Planning C: Government and Policy, 24: 191-213, 2006.

[9] Roy, B. and Vincke, P. "Multicriteria analysis: survey and new directions", European Journal of Operational Research, 8: 207-218, 1981.

[10] Vincke, P. "Analysis of multicriteria decision aid in Europe", European Journal of Operational Research 25: 160 - 168, 1986.

[11] Diakoulaki, D. and Mavrotas, G. "Stakeholder workshops and multicriteria analysis", Final report on work package 6, Sus tools - Tools for sustainability: Development and application of an integrated framework, 2004. 